\title{
Dependencies in Temporal Adjunct Clauses
}

\author{
Kiyomi Kusumoto \\ Hirosaki Gakuin University
}

\section{Introduction}

This paper examines the ambiguity in sentences like the following:

A secretary cried after/before/when each executive resigned.

It is observed in Artstein (1995) that sentences like (1) are at least two-ways ambiguous. For instance, the sentence with after has the single-time reading in which all executive resign at the same time and it is followed by the crying of a secretary, and the dependent-time reading in which each resignation at different times is followed by a possibly different secretary. ${ }^{1}$

An interesting fact also noted by Artstein is that this type of dependency is only found in temporal adjunct clauses (henceforth TACs) and not in other kinds of adjunct clauses. Thus, the following sentence is unambiguous, yielding only a single-time reading.

A secretary cried if/although/because each executive resigned.

Artstein argues that this is due to a special semantic mechanism of TACs.

In this paper, I argue on the contrary that a syntactic operation, i.e., the raising of TACs, along the line of von Stechow (1995), is responsible for the ambiguity. The paper is organized as follows: In the following section, I review Artstein's analysis and present some problematic examples. A simple syntactic analysis, namely QR is considered and rejected in section 3. Section 4 proposes a solution and its formal semantics. In the last section, I consider remaining issues.

I would like to thank Christopher Tancredi and Kyle Rawlins for comments, discussion and/or judgments. This research is partially supported by the KAKENHI grant $(17720117,20520361)$ by the Ministry of Education Culture, Science and Technology, and Japan Society for the Promotion of Sciences. All errors are of course mine.

${ }^{1}$ The sentence also has what Artstein (1995) calls an aggregate reading, according to which each executive resigned at different times and after all the resignations, one secretary cried. It may seem at first sight that this reading and the single-time reading are indistinguishable, the latter being a variant of the former. But Artstein argues that independent mechanisms to derive both readings are needed. At this point, the distinction is not important for our discussion, and so we continue to assume that relevant sentences are two-ways ambiguous. We will come back to this later. 


\section{A Semantic Approach: Artstein (1995)}

Artstein argues that TACs are temporal generalized quantifiers and they become so via an implicit existential determiner (IET). An implicit existential determiner can be applied at different stages of temporal clauses; it can be applied before or after the embedded subject (each executive) forms a VP with the predicate, as shown below:
a. A secretary cried after [IET [each executive resigned]]
b. A secretary cried after [each executive [IET [resigned]]]

(3)a yields a single-time reading. This is because, first, the implicit existential determiner takes scope over the embedded subject, and then the entire TAC takes scope over the main clause. A dependent-time reading is obtained in (3)b since the embedded subject, which takes scope over the implicit existential determiner, also takes scope over the main clause.

Let us now examine the semantics in detail. VPs denote properties of times, i.e., of type $<\mathrm{i}, \mathrm{t}>$. The VP Bill cry, for instance, denotes $\lambda t[$ cry $($ bill $)(t)]$, the property of times at which Bill cries. Two operations apply to the VP denotation to yield the truth conditions. One is called contextualization and the other existential closure. The former introduces the temporal context variable $t^{*}$, within which the sentence is evaluated. The latter existentially binds the temporal variable of the VP. The final representation is $\exists t\left[t \subseteq t^{*} \&\right.$ cry $($ bill $\left.)(t)\right] .^{2}$

VPs in TACs, however, are not existentially closed. Instead, VPs turn into temporal generalized quantifiers via an implicit existential determiner, whose semantics is $\lambda I \lambda J \exists t[I(t) \& J(t)]$. When it is applied to the embedded VP in (3)a, the existential quantifier in the implicit determiner takes scope over the embedded clause, which contains the universally quantified subject. The denotation of the TACs and the truth conditions of (3)a are given below ${ }^{3}$ :

$$
\begin{array}{ll}
\text { a. } & \lambda \mathrm{I} \exists \mathrm{t}\left[\mathrm{t} \subseteq \mathrm{t}^{*} \& \forall \mathrm{x}[\operatorname{executive}(\mathrm{x}) \rightarrow \operatorname{resign}(\mathrm{x})(\mathrm{t})] \& \mathrm{I}\left(\operatorname{after}(\mathrm{t})\left(\mathrm{t}^{*}\right)\right)\right] \\
\text { b. } & \exists \mathrm{t}\left[\mathrm { t } \subseteq \mathrm { t } ^ { * } \& \forall \mathrm { x } [ \operatorname { e x e c u t i v e } ( \mathrm { x } ) \rightarrow \operatorname { r e s i g n } ( \mathrm { x } ) ( \mathrm { t } ) ] \& \exists \mathrm { y } \left[\operatorname { s e c r e t a r y } ( \mathrm { y } ) \& \exists \mathrm { t } ^ { \prime } \left[\mathrm{t}^{\prime}\right.\right.\right. \\
& \left.\subseteq \operatorname{after}(\mathrm{t})\left(\mathrm{t}^{*}\right) \& \operatorname{cry}(\mathrm{y})\left(\mathrm{t}^{\prime}\right)\right]
\end{array}
$$

The resulting representation yields a single-time reading, which says that there is a time at which all executives resigned, and it is followed by the crying of one secretary.

\footnotetext{
${ }^{2}$ In most of his paper, Artstein does not deal with tense for the sake of simplicity. But see section 2.5. of his paper.

${ }^{3}$ The denotation of after is the following: $\llbracket$ after $\rrbracket=\lambda \mathrm{T}_{<\mathrm{it}, \mathrm{t}} \lambda \mathrm{J}\left[\mathrm{T}\left(\lambda \mathrm{t}\left[\mathrm{J}\left(\operatorname{after}(\mathrm{t})\left(\mathrm{t}^{*}\right)\right)\right]\right)\right]$, where $\operatorname{after}(\mathrm{t})\left(\mathrm{t}^{*}\right)$ is the interval spanning from the end of $\left(\mathrm{t}^{*}\right)$ to the end of $t$ when $\mathrm{t} \subseteq \mathrm{t}^{*}$; undefined otherwise.
} 
When, on the other hand, the implicit existential determiner is applied inside the VP before the subject is introduced, as in (3)b, the subject NP takes scope over the existential quantifier, which in turn takes scope over the matrix clause, yielding a dependent-time reading, as shown below:

a. $\lambda I \forall x\left[\operatorname{executive}(\mathrm{x}) \rightarrow \exists \mathrm{t}\left[\mathrm{t} \subseteq \mathrm{t} * \& \operatorname{resign}(\mathrm{x})(\mathrm{t}) \& \mathrm{I}\left(\operatorname{after}(\mathrm{t})\left(\mathrm{t}^{*}\right)\right)\right]\right]$

b. $\forall \mathrm{x}\left[\operatorname{executive}(\mathrm{x}) \rightarrow \exists \mathrm{t}\left[\mathrm{t} \subseteq \mathrm{t}^{*} \& \operatorname{resign}(\mathrm{x})(\mathrm{t}) \& \exists \mathrm{y}\left[\operatorname{secretary}(\mathrm{y}) \& \exists \mathrm{t}^{\prime}\left[\mathrm{t}^{\prime}\right.\right.\right.\right.$ $\left.\subseteq \operatorname{after}(\mathrm{t})\left(\mathrm{t}^{*}\right) \& \operatorname{cry}(\mathrm{y})\left(\mathrm{t}^{\prime}\right)\right]$

The representation in $(5) \mathrm{b}$ yields a dependent-time interpretation, according to which each executive resigned at possibly different times, and each resignation is followed by the crying of a possibly different secretary.

Under this analysis, the contrast between TACs and non-TACs in (1) and (2) regarding the availability of dependent-time readings can be explained as follows: There are two ways to bind a temporal argument of predicates. One is by the existential closure and the other is by the implicit existential determiner. The former is applied at the top of all non-TACs and the latter is introduced in TACs. ${ }^{4}$ The implicit existential determiner turns TACs into temporal generalized quantifiers, and this makes it possible for TACs to take scope over the matrix clauses. Since the implicit existential determiner is not applied in non-TACs such as if/because/although-clauses, they cannot take scope over the matrix clauses. Thus, a quantifier in these clauses may not take scope over another quantifier in the matrix clauses.

I now turn to some problematic examples. First and most problematic I believe is the example like this:

Every secretary cried after an executive resigned.

The sentence is ambiguous between the single-time reading in which a single executive resigned and it is followed by the crying of every secretary, and the dependent-time reading in which each crying follows the resignation of a possibly different executive. The latter reading cannot be obtained under Artstein's analysis. This is because the subject of the TAC can take scope over or under an implicit existential determiner, but the matrix clause always takes scope under the TAC since it is a semantic argument of the TAC, which is of a generalized quantifier type. Here are the two translations obtained:

\footnotetext{
${ }^{4}$ Existential closure is sometimes applied to TACs to derive the aggregate readings in sentences like Bill resigned after John disappeared every Friday. The sentence has a reading which is true when Bill resigned after a certain period, in which John disappeared every Friday. This reading is derived first by applying existential closure to the embedded clause John disappeared and then applying the temporal generalized quantifier every Friday. Then what is called an aggregating operation applies, which abstracts over the context variable of the TAC.
} 
a. $\exists \mathrm{t}\left[\mathrm{t} \subseteq \mathrm{t}^{*} \& \exists \mathrm{x}[\operatorname{executive}(\mathrm{x}) \& \operatorname{resign}(\mathrm{x})(\mathrm{t})] \& \forall \mathrm{y}\left[\operatorname{secretary}(\mathrm{y}) \rightarrow \exists \mathrm{t}^{\prime}\left[\mathrm{t}^{\prime}\right.\right.\right.$ $\left.\subseteq \operatorname{after}(\mathrm{t})\left(\mathrm{t}^{*}\right) \& \operatorname{cry}(\mathrm{y})\left(\mathrm{t}^{\prime}\right)\right]$

b. $\exists x\left[\operatorname{executive}(\mathrm{x}) \& \exists \mathrm{t}\left[\mathrm{t} \subseteq \mathrm{t}^{*} \& \operatorname{resign}(\mathrm{x})(\mathrm{t}) \& \forall \mathrm{y}\left[\sec r e t a r y(\mathrm{y}) \rightarrow \exists \mathrm{t}^{\prime}\left[\mathrm{t}^{\prime}\right.\right.\right.\right.$ $\left.\subseteq \operatorname{after}(\mathrm{t})\left(\mathrm{t}^{*}\right) \& \operatorname{cry}(\mathrm{y})\left(\mathrm{t}^{\prime}\right)\right]$

The former is derived when the implicit existential quantifier takes scope over the subject in the TAC, as in (8)a, and the latter is derived when it takes scope under the TAC subject as in (8)b.

a. Every secretary cried after [IET [an executive resigned]]

b. Every secretary cried after [an executive [IET resigned]]

The difference between the two interpretations is the scope relation between the existential quantifier over times and that over individuals, and the matrix subject (every secretary) always takes scope under both of them.

Second, Artstein assumes that the semantics of before is the mirror image of that of after. This is not the case, however. One piece of evidence for this is what is called a non-factual (or counter-factual) before as in:

John died before he saw his grandchildren.

The sentence does not have the same truth conditions as John saw his grandchildren after he died. Rather, it implies that he did not see his grandchildren. In order to account for cases like this and others, Anscombe (1964) and Landman (1991) among others claim that before involves a universal quantification over times whereas after an existential quantification. The truth conditions of the sentence (9) is roughly as follows:

$$
\exists t\left[\operatorname{die}(\text { john})(t) \& \forall t^{\prime}\left[\operatorname{see}(\text { john})(\text { his-grandchildren })\left(t^{\prime}\right) \rightarrow t<t^{\prime}\right]\right.
$$

This correctly predicts that the sentence is vacuously true when there is no time at which John saw his grandchildren. If this is correct, Artstein's analysis is unable to capture non-factual readings of before since temporal prepositions are always associated with an implicit existential determiner, a determiner which has an existential quantifier built into it.

To solve this problem, we may assume an implicit universal determiner, in addition to the implicit existential determiner proposed by Artstein. It might be that the former is applied to before-clauses and the latter to after-clauses. This would correctly give us non-factual readings of before, but it fails to account for single-time readings of sentences like (1): Whether the implicit universal determiner takes scope over or under the embedded subject, the resulting structures both yield a dependent-time interpretation. 


\section{A Syntactic Approach: QR}

In this section, I consider a simple syntactic approach to derive the observed ambiguity, namely by using QR. Under this analysis, the universally quantified subject in sentences like (1) is raised out of the TAC to scope over the existential subject in the matrix clause to yield a dependent-time reading, while the surface word order yields a single-time reading. This simple analysis is not considered in Artstein (1995) since it violates the locality constraint of QR.

Examples like the following are claimed to show that QR is clause-bound:

(11) One girl knows that every boy bought a present for Mary

The sentence does not have a reading in which the embedded subject every boy takes scope over the matrix subject one girl.

Fox (1995), however, argues that long-distance QR is allowed when it is semantically motivated. Consider the following example from Moltman and Szabolcsi (1994):

(12) One girl knows what every boy bought for Mary

This example minimally differs from the above example in that it takes a question complement, and this difference also makes a scope difference. The sentence allows the wide scope reading of every boy over one girl. Fox argues that this is because, in order for every boy to take scope over one girl, it has to go through an intermediate as in (13). The derivation (13)a is not semantically motivated since that is not a scope-taking element and moving every boy over that does not create any semantic differences. The derivation in (13)b, on the other hand, is semantically motivated because what is a scope-taking element and moving every boy over what yield the so-called pair-list interpretation.

a. One girl knows [every boy [that $_{\mathrm{i}}$ bought a present for Mary]]

b. One girl knows [every boy ${ }_{i}$ [what $t_{i}$ bought for Mary]]

If such analysis of $\mathrm{QR}$ is on the right track and temporal prepositions such as before and after are scope-taking elements as shown in the previous section, a QR analysis of deriving the ambiguity in TACs should not be dismissed simply because of the locality constraints. This analysis is nicely extended to the contrast between TACs and non-TACs. Recall that the dependent-time reading is not available with non-TACs like if/because/although-clauses. If these connectives are not scope-taking elements, the unavailability of dependent-time readings follows.

In what follows, I point out an interesting correlation regarding TACs and non-TACs. It seems that TACs allows wider varieties of dependencies than 
non-TACs. One is the availability of the dependent-time reading discussed throughout this paper. Another is the availability of the so-called long-distance reading observed in Geis (1970). Consider the following sentences:

(14) a. I saw Mary in New York before she claimed that she would arrive.

b. I encountered Alice after she claimed that she left.

Sentences like these are ambiguous between the so-called short-distance and long-distance interpretations. Sentence (14)a, for instance, can have the following two readings:

(15) a. short-distance: I saw Mary before the time at which she made the claim

b. long-distance: I saw Mary before her claimed time of arrival

In the short-distance reading, the matrix event time is ordered with respect to the embedding event time of the TAC, namely the time at which she made the claim. In the long-distance reading, it is ordered with respect to the embedded event time of the TA, namely her arrival time according to what she claimed.

Unlike TACs, non-TACs such as although/because clauses do not allow such a long-distance reading. Consider the following sentences from Larson (1990):

(16) a. I still respect John although he claims that he killed his mother.

b. I visited New York because Mary dreamed that Max was there.

These sentences are unambiguous. (16)a, for instance, has a short-distance reading according to which I respect John despite his claiming that he killed his mother, but not a long-distance reading which is paraphrased as "despite what John claims, namely that he killed his mother, I respect him". Similarly, (16)b does not mean that I visited New York because of what Mary dreamed, namely that Max was there. It seems then that the class of adjunct clauses that allow dependent-time readings and long-distance dependencies is the same.

Another interesting fact is cross-linguistic: Artstein (1995) reports that German does not allow a dependent-time reading. It does not allow a longdistance reading either, a fact observed in Larson (1990). Japanese is another language that does allow neither a dependent-time reading nor a long-distance reading.

If we are to account for such correlations between the availability of dependent-time readings and long-distance dependencies in TACs and non-TACs, and cross-linguistically, a simple QR analysis may not be a good candidate. 


\section{4: Another Syntactic Approach: Proposal}

This section proposes another syntactic analysis to derive the observed ambiguity. The single-time reading is derived from the surface word order. The dependenttime reading is derived first by raising the entire TAC over the main clause as in (17) $\mathrm{b}$, and then the subject of the TAC is moved out of the TAC, resulting in the structure in (17)c.
a. a secretary cried [after each executive resigned]
b. [[each executive resigned $]_{i}\left[a\right.$ secretary cried $\left[\right.$ after $\left.\left.\left.t_{i}\right]\right]\right]$
c. $\left[\right.$ each executive $\mathrm{k}_{\mathrm{k}}\left[\left[\mathrm{x}_{\mathrm{k}} \text { resigned }\right]_{\mathrm{j}}\left[\mathrm{a}\right.\right.$ secretary cried $\left.\left.\left[\mathrm{after} \mathrm{t}_{\mathrm{j}}\right]\right]\right]$

\subsection{Formal Semantics}

I start with some syntactic and semantic assumptions. Predicates come with a temporal variable in addition to usual individual variables. Thus phrases like VPs denotes properties of times, of type $<\mathrm{i}, \mathrm{t}\rangle$. Tenses are temporal variable that saturate a temporal argument slot of the predicates they attach to. They are bound by an existential quantifier.
a. Bill cried

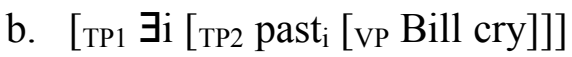

Semantically, the past tense restricts the time of the predicates to a contextually given past time.
a. $\quad \mathrm{VP}=\lambda \mathrm{t}[\operatorname{cry}(\mathrm{bill})(\mathrm{t})]$
b. $\quad$ TP $2=\left[\mathrm{t}_{\mathrm{i}} \subseteq \mathrm{t}_{\text {past }} \& \operatorname{cry}(\right.$ bill $\left.)\left(\mathrm{t}_{\mathrm{i}}\right)\right]$
c. $\mathrm{TP} 1=\exists \mathrm{t}\left[\mathrm{t} \subseteq \mathrm{t}_{\text {past }} \&\right.$ cry(bill)(t) $]$

The final representation is the translation of the sentence. It is true if and only if there is a time $t$ during a contextually given past time and Bill cried at $t$.

When a quantificational NP is the subject, it can take scope over or under the temporal existential quantifier, as shown below:
a. $\left[\exists i\right.$ past $t_{i}$ [each executive resigned]]
b. [each executive $e_{i}\left[\exists i\right.$ past $_{i}\left[x_{i}\right.$ resigned $\left.]\right]$

The former representation says that all executives resigned at the same time, and the latter says that each resigned at possibly different times.

Let us now turn to the syntax and semantics of TACs. Recall the short-distance and long-distance ambiguity observed by Geis (1970), discussed in the previous section. The relevant examples are repeated here: 
(21) a. I saw Mary in New York before she claimed that she would arrive.

b. I encountered Alice after she claimed that she left.

Larson (1990) claims that the kind of ambiguity observed in the TACs is similar to what we find in $w h$-questions and relative-clauses.

a. When did Mary claim that she would arrive?

b. I saw Mary in New York before the time at which she claimed that she would arrive

These sentences are ambiguous. (22)a, for example, can either be a question asking for the time Mary made the claim, or the time of her arrival according to her claim. Similarly for (22)b. Furthermore, these constructions are generally assumed to have an operator movement. In wh-questions, wh-words such as when may originate in the matrix or embedded clauses, and depending on where it originates, the ambiguity arises. Similarly, relative-clauses are assumed to have an operator movement. Based on these facts, Larson (1990) proposes a null temporal operator movement in TACs.

(23) a. I saw Mary in New York before $\mathrm{OP}_{\mathrm{i}}$ [she claimed $\mathrm{t}_{\mathrm{i}}$ [that she would arrive]]

b. I saw Mary in New York before $\mathrm{OP}_{\mathrm{i}}$ [she claimed [that she would arrive $\left.t_{i}\right]$ ]

A null operator originates either in the embedding clause or embedded clause of the TAC and moves to the top of the TAC. Evidence for such a movement analysis comes from the fact that the observed ambiguity disappears when the TAC contains an island. The following sentence is unambiguous and only has a short-distance interpretation:

(24) I saw Mary in New York before she made the claim that she would arrive.

If a long-distance reading is due to a null operator movement from the embedded clause in the TAC, the unavailability of such a reading in sentences like (24) follows from a general locality constraint on movement.

I follow Larson (1990) and von Stechow (2002), and assume that TACs employ a null temporal operator movement. A null operator is generated as a complement of a null preposition at and moves in front of the embedded clause. A simple embedded clause such as (after) Sue arrived has a structure like the following: 
(25)

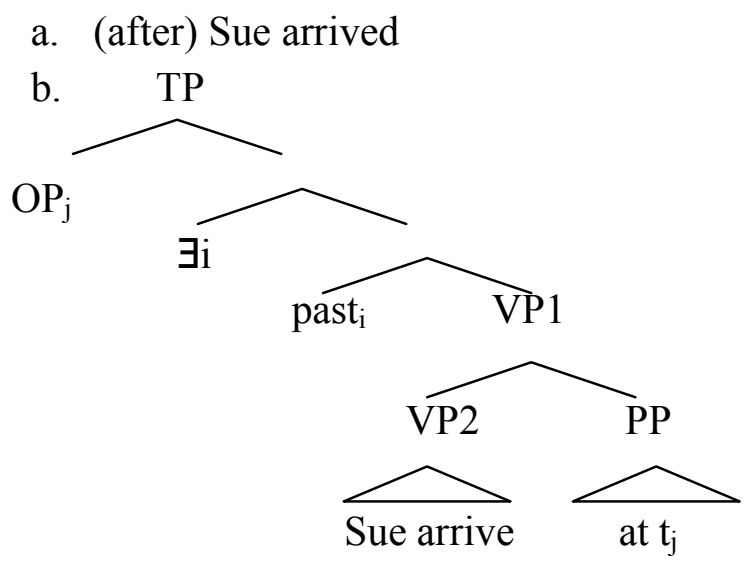

I propose that a null operator itself is semantically vacuous, but when moved, it leaves a trace of type i. ${ }^{5}$ Following Heim and Kratzer (1998), I assume that the index of a moved element acts as a lambda abstractor over the index of its trace.
a. $\quad P P=\lambda \mathrm{t}\left[\mathrm{t}=\mathrm{t}_{\mathrm{j}}\right]$
b. $\quad \mathrm{VP} 1=\lambda \mathrm{t}\left[\operatorname{arrive}(\right.$ sue $\left.)(\mathrm{t}) \& \mathrm{t}=\mathrm{t}_{\mathrm{i}}\right]$
c. $\quad \mathrm{TP}=\lambda \mathrm{t}_{\mathrm{j}} \exists \mathrm{t}\left[\mathrm{t} \subseteq \mathrm{t}_{\text {past }} \&\right.$ arrive(sue $\left.)(\mathrm{t}) \& \mathrm{t}=\mathrm{t}_{\mathrm{j}}\right]$

The temporal prepositions after and before translate as a function of type $<<\mathrm{i}, \mathrm{t}\rangle,\langle\mathrm{i}, \mathrm{t}\rangle>$. A difference between the two is that after involves an existential quantification whereas before involves a universal quantification.

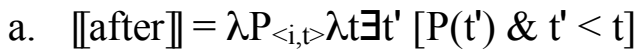
b. [before $\rrbracket=\lambda \mathrm{P}_{<\mathrm{i}, \mathrm{t}} \lambda \lambda t \forall \mathrm{t}^{\prime}\left[\mathrm{P}\left(\mathrm{t}^{\prime}\right) \rightarrow \mathrm{t}<\mathrm{t}^{\prime}\right]$

Now let us see how TACs such as after-clauses modify the main clause. After takes the embedded TP as its complement. The entire TAC adjoins to the matrix VP.

\footnotetext{
${ }^{5}$ Larson (1990) says nothing about the semantics of such temporal operators. The current analysis differs from von Stechow's (2002), who proposes that the operator means something like 'the smallest time'.
} 
(28)

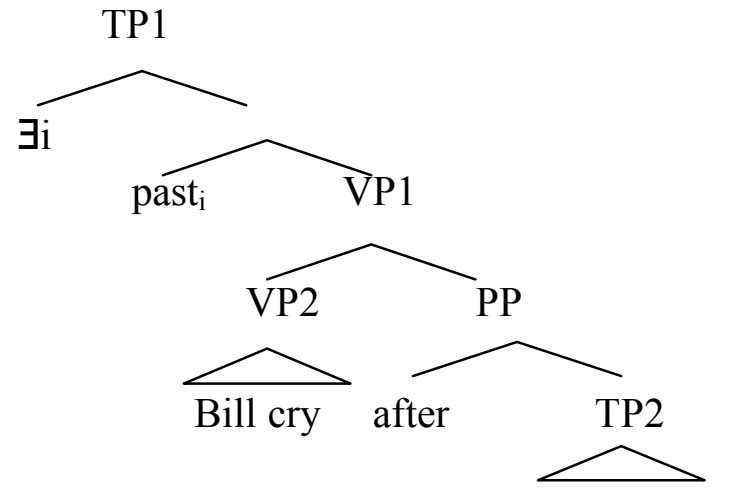

Sue arrived

The after-clause (i.e., the PP) denotes the property of times after a contextually relevant past event time of Sue's leaving. It 'modifies' the lower VP by adjoining to it. Semantically, we get the intersection of the denotations of the PP and the VP2, as in (29)d.
a. $\quad \mathrm{TP} 2=\lambda \mathrm{t}_{\mathrm{j}} \exists \mathrm{t}\left[\mathrm{t} \subseteq \mathrm{t}_{\text {past }} \&\right.$ arrive $($ sue $\left.)(\mathrm{t}) \& \mathrm{t}=\mathrm{t}_{\mathrm{j}}\right]$
b. $P P=\lambda \mathrm{t} \exists \mathrm{t}^{\prime} \exists \mathrm{t}^{\prime \prime}\left[\mathrm{t}^{\prime \prime} \subseteq \mathrm{t}_{\text {past }} \&\right.$ arrive(sue $\left.)\left(\mathrm{t}^{\prime \prime}\right) \& \mathrm{t}^{\prime \prime}=\mathrm{t}^{\prime} \& \mathrm{t}^{\prime}<\mathrm{t}\right]$
c. $\mathrm{VP} 2=\lambda \mathrm{t}[\mathrm{cry}(\mathrm{bill})(\mathrm{t})]$
d. $\quad \mathrm{VP} 1=\lambda \mathrm{t}\left[\operatorname{cry}\left(\right.\right.$ bill)(t) $\& \exists \mathrm{t}^{\prime} \exists \mathrm{t}^{\prime \prime}\left[\mathrm{t}^{\prime \prime} \subseteq \mathrm{t}_{\text {past }} \&\right.$ arrive(sue) $\left(\mathrm{t}^{\prime \prime}\right) \& \mathrm{t}^{\prime \prime}=\mathrm{t}^{\prime} \& \mathrm{t}^{\prime}<$ t]
e. $T P 1=\exists \mathrm{t}\left[\mathrm{t} \subseteq \mathrm{t}_{\text {past }} \& \operatorname{cry}\left(\right.\right.$ bill)(t) $\& \exists \mathrm{t}^{\prime} \exists \mathrm{t}^{\prime \prime}\left[\mathrm{t}^{\prime \prime} \subseteq \mathrm{t}_{\text {past }} \&\right.$ arrive(sue)(t") \& $\left.\mathrm{t}^{\prime \prime}=\mathrm{t}^{\prime} \& \mathrm{t}^{\prime}<\mathrm{t}\right]$

The final representation says that there is a time at which Bill cried and another time at which Sue arrived, both during a contextually relevant past time, and Bill's crying time is after Sue's arrival time.

Let us now come back to dependent-time interpretations of TACs. Our proposal is that it is derived first by raising the complement clause of the temporal preposition as in (30)a. The embedded quantificational subject is moved from this position to adjoin to the entire sentence.

(30) a. $\quad{ }_{\mathrm{TP} 2} \exists \mathrm{m}$ past $\mathrm{m}_{\mathrm{m}}$ Each executive resigned $]_{\mathrm{j}}\left[_{\mathrm{TP1}} \exists \mathrm{i}\right.$ past ${ }_{\mathrm{i}}\left[_{\mathrm{VP1}}\left[{ }_{\mathrm{VP} 2}\right.\right.$ a secretary cry] [pP after $\left.\left.\mathrm{t}_{\mathrm{j}} \mathrm{j}\right]\right]$

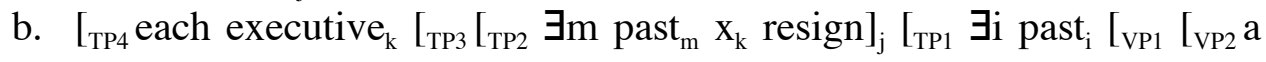
secretary cry] [PP after $\left.\left.\left.\left.\left.\mathrm{t}_{\mathrm{j}}\right]\right]\right]\right]\right]$

Here are semantic representations at different stages:
a. $\quad \mathrm{TP} 1=\lambda \mathrm{P}_{<, \mathrm{t},} \exists \mathrm{t}^{\prime}\left[\mathrm{t}^{\prime} \subseteq \mathrm{t}_{\text {past }} \& \exists \mathrm{y}\left[\sec r e t a r y(\mathrm{y}) \& \operatorname{cry}(\mathrm{y})\left(\mathrm{t}^{\prime}\right) \& \exists \mathrm{t}^{\prime \prime}\left[\mathrm{P}\left(\mathrm{t}^{\prime \prime}\right) \& \mathrm{t}^{\prime \prime}\right.\right.\right.$ $\left.\left.<\mathrm{t}^{\prime}\right]\right]$
b. $\quad \mathrm{TP} 2=\lambda \mathrm{t}_{\mathrm{i}} \exists \mathrm{t}^{\prime}\left[\mathrm{t}^{\prime} \subseteq \mathrm{t}_{\text {past }} \& \operatorname{resign}(\mathrm{x})\left(\mathrm{t}^{\prime}\right) \& \mathrm{t}^{\prime}=\mathrm{t}_{\mathrm{i}}\right]$ 
c. $\mathrm{TP} 3=\exists \mathrm{t}^{\prime}\left[\mathrm{t}^{\prime} \subseteq \mathrm{t}_{\text {past }} \& \exists \mathrm{y}\left[\sec r e t a r y(\mathrm{y}) \& \operatorname{cry}(\mathrm{y})\left(\mathrm{t}^{\prime}\right) \& \exists \mathrm{t}^{\prime \prime} \exists{ }^{\prime \prime \prime}\left[\mathrm{t}^{\prime \prime \prime} \subseteq \mathrm{t}_{\text {past }} \&\right.\right.\right.$ $\left.\operatorname{resign}(\mathrm{x})\left(\mathrm{t}^{\prime \prime \prime}\right) \& \mathrm{t}^{\prime \prime \prime}=\mathrm{t}^{\prime \prime} \& \mathrm{t} "<\mathrm{t}^{\prime}\right]$

d. $\quad$ TP4 $=\forall \mathrm{x}\left[\operatorname{executive}(\mathrm{x}) \rightarrow \exists \mathrm{t}^{\prime}\left[\mathrm{t}^{\prime} \subseteq \mathrm{t}_{\text {past }} \& \exists \mathrm{y}\left[\sec r e t a r y(\mathrm{y}) \& \operatorname{cry}(\mathrm{y})\left(\mathrm{t}^{\prime}\right)\right.\right.\right.$ $\& \exists t^{\prime \prime} \exists^{\prime \prime \prime}\left[\mathrm{t}^{\prime \prime} \subseteq \mathrm{t}_{\text {past }} \& \operatorname{resign}(\mathrm{x})\left(\mathrm{t}^{\prime \prime \prime}\right) \& \mathrm{t}^{\prime \prime}=\mathrm{t}^{\prime \prime} \& \mathrm{t}^{\prime \prime}<\mathrm{t}^{\prime}\right]$

The final line correctly represents a dependent-time interpretation.

\subsection{Some Consequences}

The observed ambiguity of quantifiers in TACs disappears when TACs contain a pronoun bound by a quantifier in the main clause:

[A secretary $]_{i}$ cried after each executive hit her $r_{\text {. }}$

The sentence above is unambiguous; it lacks a dependent-time reading. This fact follows straightforwardly under the current analysis. In order to yield the dependent-time reading, the entire $\mathrm{TAC}$ has to move to take scope over the matrix clause, and the resulting structure is the following:

\section{[[each executive hit her $]_{\mathrm{j}}\left[[\text { a secretary }]_{\mathrm{i}}\right.$ cried $\left[\right.$ after $\left.\left.\left.\mathrm{t}_{\mathrm{j}}\right]\right]\right]$}

The pronoun her in the TAC is no longer bound by the matrix subject. The unavailability of the bound variable reading of her and the dependent-time reading at the same time cannot be accounted for under Artstein's semantic analysis nor under a simple QR analysis.

Second, I show that the contrast between TACs and non-TACs regarding the availability of dependent-time readings. I have argued that the raising of the embedded TP over the matrix clause is a necessary step to yield dependent-time readings. Doing so out of TACs does not create any syntactic or semantic deviancy. I argue that raising out of non-TACs on the contrary results in uninterpretability. Let us see why. If-clauses, for instance, are generally assumed to serve as a restrictor of a covert universal quantifier over possible worlds. A rough translation of the sentence (34)a would be something like (34)b.

a. A secretary cried if each executive resigned.

b. $\forall \mathrm{w}[\mathrm{w}$ is accessible from the actual world and each executive cried in $\mathrm{w} \rightarrow$ a secretary cried in $\mathrm{w}]$

If the syntactic representation of sentences contains world variables, moving the embedded clause to take scope over the entire sentence would lead to an LF in which the world variable associated with the embedded verb resign is left unbound.

Lastly, let us consider languages like German and Japanese that allow 
neither long-distance readings nor dependent-time readings. I have argued, following Larson (1990), that long-distance readings in languages like English are due to a null temporal operator movement. If so, there are two ways to account for the unavailability of such readings in languages like German and Japanese. One is to say that some locality constraint prohibits a null temporal operator in these languages from moving long-distance. The other is to say that they do not employ such a null temporal operator movement.

In Arregui and Kusumoto (1998), it was argued that Japanese TACs do not involve a null operator movement. Evidence for this analysis comes from the behavior of tenses in TACs. In languages like English, tenses in TACs behave like those in root clauses, that is, they are absolute tenses. This means that despite the fact that tenses in TACs are syntactically embedded under the scope of tenses in the matrix clauses, they are evaluated with respect to the evaluation time of the sentence, not with respect to the tense immediately dominating them. Under the current analysis, this is accomplished since the past tense in TACs like the following is bound by an existential quantifier immediately dominating it.
a. (after) Sue arrived
b. $\mathrm{OP}_{\mathrm{j}} \exists \mathrm{i}$ past $\mathrm{p}_{\mathrm{i}}$ Sue arrive at $\mathrm{t}_{\mathrm{j}}$

At this point, i.e., before the operator meaning is applied, the structure $\exists i$ past $_{i}$ Sue arrive at $t_{j}$ denotes a truth value, of type $t$. This is not the right type since temporal prepositions such as after requires their complement be of type $<\mathrm{i}, \mathrm{t}\rangle$. When the null operator with a moved index is applied, the complement clause becomes of type $<\mathrm{i}, \mathrm{t}>$, an appropriate type to combine with after. Thus, in languages like English, in which embedded tenses are interpreted as absolute tenses, a null operator movement is necessary for interpretability.

In languages like Japanese, however, it is agued that embedded tenses are relative tenses, i.e., tenses that are not evaluated with respect to the evaluation time of the sentence but to the dominating tenses. Consider the following examples:

a. Junko-ga kaer-u/*kaet-ta maeni Satoshi-ga ki-ta.

J-nom leave-pres/leave-past before S-nom come-past

'Satoshi came before Junko left'

b. Junko-ga kaer-u/*kaet-ta maeni Satoshi-ga kur-u.

J-nom leave-pres/leave-past before S-nom come-pres

'Satoshi will come before Junko leaves'

a. Junko-ga *kaer-u/kaet-ta atoni Satoshi-ga ki-ta.

J-nom leave-pres/leave-past after S-nom come-past

'Satoshi came after Junko left' 


\section{b. Junko-ga *kaer-u/kaet-ta atoni Satoshi-ga kur-u. \\ J-nom leave-pres/leave-past after S-nom come-pres 'Satoshi will come after Junko leaves'}

In Japanese, tenses in maeni 'before'-clauses are always present and those in atoni 'after'-clauses are always past, whether tenses in the matrix clauses are present or past. This means that they are not interpreted as absolute tenses. If they were, the sentences would yield temporally incoherent interpretations. Tenses in TACs in Japanese are not interpreted in the same way as matrix tenses. That is, they are not existentially closed. How are they interpreted then? I propose, following the idea developed in Arregui and Kusumoto (1998), that they are bound by temporal prepositions themselves, as shown below:

\section{$\left[\mathrm{PP}\left[{ }_{\mathrm{TP}}[\mathrm{VP}\right.\right.$ Junko-ga kaer- $]$ pres $\left._{\mathrm{i}}\right]$ maeni $\left._{\mathrm{i}}\right]$}

The index of the preposition correctly gives the right type $(<\mathrm{i}, \mathrm{t}>)$ for the semantics of such prepositions without the help of a null temporal operator. This way of interpreting embedded tenses would not give us an access to further embedded tenses, excluding long-distance dependencies in such languages. If this analysis is on the right track, the TP complement of the temporal preposition in languages that do not have a null temporal operator movement cannot be raised because the raising would leave the embedded tense unbound. This correctly predicts the correlation between the availability of dependent-time readings and that of long-distance dependencies, i.e., languages either allow both types of dependencies or neither ones.

\section{Remaining Issues}

In this section, I discuss long-distance readings of TAC in more detail. Some data regarding this phenomenon is problematic to theories like Artstein's that derive long-distance dependencies by means of abstraction. Other data are problematic to analyses that rely on movement, like the one presented here.

One problem is pointed out by von Stechow (1995), who argues against the analysis of temporal modifiers in Pratt and Francez (2001) which Artstein's analysis is partly based on. It is also noted by Artstein himself. Artstein argues against a movement analysis like Larson's and derives long-distance readings as follows. Unlike other TACs, the complement clause of the temporal preposition like (39)a may choose not to have a temporal existential determiner applied at this point. Instead, the verb's temporal argument may be existentially closed, resulting the representation in (39)b:

a. (after) Alice claimed that she left 
b. $\exists \mathrm{t}\left[\mathrm{t} \subseteq \underline{\mathrm{t}^{*}} \& \operatorname{claim}\left(\mathrm{w}^{*}\right)\left(\lambda \mathrm{w} \exists \mathrm{t}^{\prime}\left[\mathrm{t}^{\prime} \subseteq \underline{\mathrm{t}^{*} *} \&\right.\right.\right.$ leave $(\mathrm{w})($ alice $\left.\left.)\left(\mathrm{t}^{\prime}\right)\right]\right)($ alice $\left.)(\mathrm{t})\right]$

At this point, an abstraction over a temporal context variable applies. Since there are two temporal context variables in (39)b, we have two possible representations:

a. $\lambda \mathrm{t}^{*} \exists \mathrm{t}\left[\mathrm{t} \subseteq \underline{\mathrm{t}^{*}} \& \operatorname{claim}\left(\mathrm{w}^{*}\right)\left(\lambda \mathrm{w} \exists \mathrm{t}^{\prime}\left[\mathrm{t}^{\prime} \subseteq \mathrm{t}^{\prime *} \&\right.\right.\right.$ leave(w)(alice)(t')])(alice) $(\mathrm{t})]$

b. $\lambda \underline{t^{\prime} * \exists t}\left[t \subseteq t^{*} \& \operatorname{claim}\left(w^{*}\right)\left(\lambda w \exists t^{\prime}\left[t^{\prime} \subseteq \underline{t^{\prime} *} \&\right.\right.\right.$ leave(w)(alice)(t')])(alice) (t)]

When we abstract over the temporal context variable in the embedding clause in the TAC (i.e., $t^{*}$ ), we get the representation in (40)a. (40)b is the result of abstracting over the context variable in the embedded clause (i.e., $t^{*} *$ ). After this stage, contextualization and a temporal existential determiner apply before they are combined with the matrix clause. The former yields a short-distance reading and the latter a long-distance reading.

Now the problem: The abstraction operation assumed here is semantic and thus there should be nothing wrong with abstracting over the temporal context variable in the embedded clause, $t^{\prime *}$, out of an island in the following representation:

$$
\begin{aligned}
& \lambda \underline{\mathrm{t}^{\prime} * \exists \mathrm{t}}\left[\mathrm{t} \subseteq \mathrm{t}^{*} \& \text { make-the-claim }\left(\mathrm{w}^{*}\right)\left(\lambda \mathrm{w} \exists \mathrm{t}^{\prime}\left[\mathrm{t}^{\prime} \subseteq \underline{\mathrm{t}^{\prime} *} \& \text { leave }(\mathrm{w})(\text { alice })\left(\mathrm{t}^{\prime}\right)\right]\right)\right. \\
& (\text { alice })(\mathrm{t})]
\end{aligned}
$$

If this is possible, it would yield a long-distance reading for sentences that contain an island, which should be prohibited.

Artstein acknowledges this problem and yet argues that no-movement analyses such as his fare better. He considers examples like the following:

I saw Mary after each boy claimed that she left.

This sentence has a universally quantified subject in the TAC and hence possibly yields a single-time/aggregate or dependent-time ambiguity. ${ }^{6}$ It also has an embedding inside the TAC, which may yield short-distance or long-distance interpretations. Thus the sentence should result in a four-way ambiguity, as shown in (43). The fact is that the sentence is only three-ways ambiguous, lacking a long-distance/dependent-time reading.

\footnotetext{
${ }^{6}$ In considering the readings of examples like (42), Artstein does not distinguish single-time and aggregate readings, and uses the label of 'aggregate' reading for both. This is perhaps because he concentrates on the lack of the long-distance/dependent-time readings. We will come back to this point later.
} 
(43) a. short-distance, single-time/aggregate: I saw Mary after the (last) claiming time

b. long-distance, single-time/aggregate: I saw Mary after the (last) claimed departure time

c. short-distance/dependent-time: I saw Mary after each act of claiming

d.* long-distance/dependent-time: I saw Mary after each claimed departure time

Artstein argues that the unavailability of the long-distance/dependent-time reading follows. First let us consider the computation where existential closure applies, followed by an abstraction operation, as in (39) and (40). We get the following two representations:

a. $\lambda \mathrm{I} \exists \mathrm{t}\left[\mathrm{t} \subseteq \mathrm{t}^{*} \& \forall \mathrm{x}\left[\operatorname{boy}(\mathrm{x}) \rightarrow \exists \mathrm{t}^{\prime}\left[\mathrm{t}^{\prime} \subseteq \mathrm{t} \& \operatorname{claim}\left(\mathrm{w}^{*}\right)\left(\lambda \mathrm{w} \exists \mathrm{t}^{\prime \prime}\left[\mathrm{t}^{\prime \prime} \subseteq \mathrm{t}^{*} \&\right.\right.\right.\right.\right.$ leave $\left.\left.\left.\left.(\mathrm{w})(\operatorname{she})\left(\mathrm{t}^{\prime \prime}\right)\right]\right)(\mathrm{x})\left(\mathrm{t}^{\prime}\right)\right] \& \mathrm{I}\left(\operatorname{after}(\mathrm{t})\left(\mathrm{t}^{*}\right)\right)\right]$

b. $\lambda \mathrm{I} \exists \mathrm{t}\left[\mathrm{t} \subseteq \mathrm{t}^{*} \& \forall \mathrm{x}\left[\operatorname{boy}(\mathrm{x}) \rightarrow \exists \mathrm{t}^{\prime}\left[\mathrm{t}^{\prime} \subseteq \mathrm{t}^{*} \& \operatorname{claim}\left(\mathrm{w}^{*}\right)\left(\lambda \mathrm{w} \exists \mathrm{t}^{\prime \prime}\left[\mathrm{t}^{\prime \prime} \subseteq \mathrm{t} \&\right.\right.\right.\right.\right.$ leave $\left.\left.\left.\left.(\mathrm{w})(\operatorname{she})\left(\mathrm{t}^{\prime \prime}\right)\right]\right)(\mathrm{x})\left(\mathrm{t}^{\prime}\right)\right] \& \mathrm{I}\left(\operatorname{after}(\mathrm{t})\left(\mathrm{t}^{*}\right)\right)\right]$

These are derived when an abstraction is over the embedding or embedded context variables. The former yields the short-distance, aggregate reading whereas the latter the long-distance, aggregate reading.

In addition to the above operation, Artstein claims that there are 'normal' ways to interpret TACs, that is to apply the implicit existential determiner either right above or below the quantified subject.

a. after [IET [each boy claimed that she left]]

b. $\lambda \mathrm{I} \exists \mathrm{t}\left[\mathrm{t} \subseteq \mathrm{t}^{*} \& \forall \mathrm{x}\left[\operatorname{boy}(\mathrm{x}) \rightarrow \operatorname{claim}\left(\mathrm{w}^{*}\right)\left(\lambda \mathrm{w} \exists \mathrm{t}^{\prime}\left[\mathrm{t}^{\prime} \subseteq \mathrm{t}^{*} \&\right.\right.\right.\right.$ leave $(\mathrm{w})(\mathrm{she})$ $\left.\left.\left.\left.\left(\mathrm{t}^{\prime}\right)\right]\right)(\mathrm{x})(\mathrm{t})\right] \& \mathrm{I}\left(\operatorname{after}(\mathrm{t})\left(\mathrm{t}^{*}\right)\right)\right]$

(46) a. after [each boy [IET claimed that she left]]

b. $\lambda \operatorname{I} \forall \mathrm{x}\left[\operatorname{boy}(\mathrm{x}) \rightarrow\left[\exists \mathrm{t}\left[\mathrm{t} \subseteq \mathrm{t}^{*} \& \operatorname{claim}\left(\mathrm{w}^{*}\right)\left(\lambda \mathrm{w} \exists \mathrm{t}^{\prime}\left[\mathrm{t}^{\prime} \subseteq \mathrm{t}^{*} * \&\right.\right.\right.\right.\right.$ leave(w)(she) $\left.\left.\left.\left.\left(\mathrm{t}^{\prime}\right)\right]\right)(\mathrm{x})(\mathrm{t})\right] \& \mathrm{I}\left(\operatorname{after}(\mathrm{t})\left(\mathrm{t}^{*}\right)\right)\right]$

The former yields a short-distance/single-time reading (43)a, and the latter a short-distance/dependent-time reading (43)c. If these four are the only options to interpret TACs, it means that there are no ways to derive a long-distance/ dependent-time reading.

Now let us examine single-time and aggregate readings in detail. The operation to derive (44), namely, existential closure followed by abstraction over a context variable is first introduced to derive the so-called aggregate readings. Thus the readings derived by (44) are short-distance or long-distance aggregate, not s single-time, readings respectively. The representations in (45) and (46) are derived without using the aggregating operation, and therefore do not yield 
aggregate readings. That is, under Artstein's system, only four readings are derived, namely, short- distance/aggregate, long-distance/aggregate, shortdistance/single-time, and short-distance/dependent readings. While it correctly predicts the unavailability of long-distance/dependent readings, it misses to derive an available long-distance/single-time reading. If Artstein is right about distinguishing the single-time and aggregate readings, this is another problem.

Let come back to a movement analysis. The unavailability of longdistance/dependent readings is unexpected under a movement analysis, Artstein argues, because an explicit temporal operator movement such as the following has a so-called pair-list reading with a long-distance dependency.

When did each boy claim that Mary left?

This question sentence can be answered with "Adam claimed she left at noon, Bill claimed she left at 13:00, etc". If overt wh-movement and covert temporal operator movement in TACs are treated on a par, dependent-time readings should be allowed with long-distance dependencies. I do not have a solution to this problem, but would like to point out one interesting fact. Relative clauses seem to behave similarly to TACs rather than to wh-movement, despite that they are assumed to involve an overt relative pronoun movement. Consider the following:

I saw Mary after the time at which each boy claimed that she left.

It is difficult, if not impossible, to get a long-distance/dependent-time reading with this sentence. If so, there may be an independent reason to block such a reading in TACs.

\section{References}

Anscombe, G. E. M.: 1964, 'Before and After', Philosophical Review 73, 3-24.

Arregui Ana and Kiyomi Kusumoto: 1998, 'Tense in Temporal Adjunct Clauses', Proceedings of Semantics and Linguistic Theory VIII, 1-18.

Artstein, Ron: 2005, 'Quantificational Arguments in Temporal Adjunct Clauses', Linguistics and Philosophy 28, 541-597.

Fox, Danny: 1995, 'Economy and Scope', Natural Language Semantics 3, 283-341.

Geis, Michael: 1970, Adverbial Subordinate Clauses in English, Doctoral dissertation, MIT.

Heim, Irene and Angelika Krazter: 1998, Semantics and Generative Grammar, Blackwell Publishing, Oxford.

Landman, Fred: 1991, Structure for Semantics, Kluwer Academic Publishers, Dordrecht. 
Larson, Richard: 1990, 'Extraction and Multiple Selection in PP', The Linguistic Review 7, 169-182.

Moltmann, Friederike and Anna Szabolcsi: 1994, 'Scope Inversion with Pair-List Quantifiers', Proceedings of North East Linguistic Society 24, 381-395, GLSA, University of Massachusetts Amherst.

Pratt, Ian and Nissim Francez: 2001, 'Temporal Prepositions and Temporal Generalized Quantifiers', Linguistics and Philosophy 24, 187-222.

Von Stechow, Arnim: 2002, 'Temporal Prepositional Phrases with Quantifiers: Some Additions to Pratt and Francez (2001)', Linguistics and Philosophy 25, 755-800. 